Guilherme Marcos de La Penha, Ph.D (University of Hous-

ton) em mecânica de sólidos e matemática aplicada. Post Doctor Fellow (Carnegie Institut of Technology) em mecânica do contínuo, é vice-presidente do Conselho Nacional de Ciência e Tecnologia CNPq.

\title{
Sobre as histórias da história da mecânica do século XVIII
}

Introdução - o século XVIII tem sido reconhecido como um período em separado na maioria dos relatos históricos da matemática e da mecânica. Isso parece se dar menos pelas características das ciências matemáticas naquele século e mais pelo fato de o mesmo situar-se entre dois excitantes períodos no desenvolvimento da matemática e da mecânica: os séculos XVII e XIX.

Relatos históricos disponíveis criam representações distintas de ambos esses períodos, com pessoas e realizações colocadas claramente em primeiro plano - imagens bem estruturadas na memória comum da comunidade dos cientistas matemáticos. O século XVIII não goza dessa mesma clareza, parecendo meramente que as realizações dessa época tão somente conduziram as ciências matemáticas dos fins do século XVII às do século XIX. Não obstante a existência de grandes cientistas - os Bernoullis, Euler, Lagrange e a gigantesca quantidade de trabalho realizado, parece impossivel caracterizar isso sob uma formulação simples e clara, isto é, sob uma forma estruturada, como o temos para o século que o precedeu e o que o sucedeu.

\section{As Histórias da mecânica}

A história das ciências matemáticas amolda a memória comum dos cientistas matemáticos; essa memória não é detalhada, consiste de retratos gerais como aqueles existentes para os séculos XVII e XIX; como a tentativa de fundamentação da mecânica clássica por Galileu, Huygens e Newton e a invenção do cálculo por Newton e Leibniz no primeiro, enquanto no segundo a fundamentação da análise clássica por Cauchy e Weierstrass e a criação da análise complexa por estes e Riemann, a criação da álgebra moderna por Galois, Dedekind e Kronecker e os primórdios da teoria dos conjuntos e estudos dos fundamentos da matemática por Cantor. 
1. J. E. Montucla (1725-1799) - Historie des mathématiques, (1 ed. em 2 vols.), nova edição em 4 vols. , Paris, 1799-1802. (Os dois últimos volumes referentes ao séc. XVIII foram completados por Lalande).
2. M. Cantor (1829-1920) Vorlesungen über geschichte der Mathematik, 4 vols., Leipizig, 1880-1908.

3. L. Euler (1707-1783) - Introductio in analysin infinitorum, 2 vols., Lausanne, 1748 - Opera omnia (I) 8-9

4. L. Euler - Institutiones calculi differentialis, São Petersburgo, 1755, Opera omnia (I) 10.
Porém uma representação histórica desestruturada, uma história sem pontos de realce, não é retida na memória. Para a história da ciência vale igualmente o dito de H. Poincaré, "La science est constituée de faits, tout comme une maison est faite de briques, mais une accumulation de faits ne forme pas plus la science qu' un tas de briques ne fait une maison".

Vejamos rapidamente como aconteceu que uma série de histórias gerais da matemática e da mecânica deixaram a visão do século XVIII tão vaga e desestruturada como se deu até bem recentemente.

A primeira história geral da matemática a incluir o século XVIII é a Historie des mathématiques de Montucla ${ }^{1}$, os últimos dois volumes que se referem especificamente a esse século sendo o trabalho de Lalande após a morte do autor. Tem-se assim a visão do período a partir de um contemporâneo, malgrado a perda da estrutura devido à proximidade, elaé, no entanto, viva. A primeira surpresa no trabalho de Montucla é a diversidade do que entende por matemática, dividida como usual no século XVIII em matemática pura e matemática mista, esta última incluindo entre outras a ótica; a mecânica teórica ou analítica; as máquinas; a astronomia planetária, física e observacional; a navegação e a construção de navios, etc...

O objeto da matemática na visão da época, reproduzida por Montucla, é "La science des rapports de grandeur ou de nombre, que peuvent avoir ent'elles toutes les choses qui sont susceptibles d'augmentation ou de diminuition. "Isso explica a terminologia 'pura' e 'mista', a primeira tratando de relações entre quantidades e respectivamente dos objetos que medem ou contam, e a segunda lidando com quantidades e suas relações, conforme ocorrem em objetos naturais que podem ser contados ou medidos. A terminologia, e mesmo a sua equivalente inglesa, pura e especulativa, é de fato apropriada e melhor que a pretensa divisão atual em 'pura' e 'aplicada', que não atenta à natureza dialética do uso da matemática e sugere que ou se pratica a matemática pura ou toma-se um pacote pronto de matemática aplicando-o em outra coisa qualquer.

A representação que emerge de Montucla para a mecânica teórica do século XVIII concentra-se em problemas - tautócronas, corda vibrante, movimento de projéteis sob resistência do ar, hidrodinâmica e nos vários princípios: das forças vivas, da ação mínima, das acelerações reversas (D'Alembert) desenvolvidos com a finalidade de buscar uma ciência matemática geral da mecânica. Segundo sua visão, essa tentativa foi coroada por Lagrange, que "reduziu todos os problemas a fórmulas gerais, cujo desenvolvimento provê todas as equações necessárias à solução de cada problema".

Nenhuma visão da matemática do século XVIII emerge da massa de detalhes no trabalho de Cantor ${ }^{2}$, Vorlesungen uber Geschichte der Mathematik, ao que parece ele vê apenas três relevos naquele período: a questão de prioridade entre Leibniz e Newton acerca da invenção do cálculo, a Introductio in analysin infinitorum ${ }^{3}$ (1748) de Euler e seu Institutiones calculi differentialis' (1755) porém a apresentação dificilmente fornece um foco, os capítulos sobre os 
5. C. B. Boyer - A History of mathematics, J. Wiley, N. York, 1968, p. 510. (disponivel em tradução brasileira).

6. J. L. Lagrange (1736-1813) Mécanique analytique, 2 vols., Paris, 1788, Oeuvres, 11-12.

7. E. Mach (1836-1916) - Die Mechanik in ihrer Entwicklung historischkritisch dargestellt, 11 ed. 1833), 9 ed., Brockhaus, Leipzig, 1933. (uma imperfeita tradução para o espanhol, de título Desarollo historico critico de la mecanica, referente à 7 ed., foi publicada por Espasa Calpe, B Aires, 1949)
8. R. Dugas (1897-1957) - Historie de la mécanique, Le Griffon, Neuchàtel, 1950. lo autor discorre mais extensamente sobre o século XVII em La Mécanique au XVIIe Siècle, Le Griffon, Neuchâtel, 1954) livros de Euler sendo extratos de seus conteúdos. É perdida assim a vivacidade da descrição de Montucla sem qualquer ganho de estrutura. Em trabalhos subseqüentes o século XVIII é sempre subestimado, seja por sua carência de fundamentos seguros da matemática seja pela infrutífera busca de métodos gerais, até o ponto de ser rotulado como 'uma infelicidade' por situar-se entre os séculos XVII e XIX5.

Quanto à mecânica do século XVIII, a visão de Montucla acompanhou a de Lagrange ${ }^{6}$ e assim permaneceu invariante por muito tempo. Já em 1883, através de um livro influente de Mach, Die Mechanik in ihrer Entwicklung historischkritisch dargestellt ${ }^{7}$, este arguia que a ciência desenvolve-se em três fases: acumulação de observações dos fenômenos, dedução lógica e teórica de certos fenômenos a partir de outros e a fase do desenvolvimento formal, na qual certas observações são reconhecidas como princípios básicos da ciência e as deduções organizadas em uma unidade teórica. Nesse esquema a 'economia de pensamento' demanda que a dedução de fenômenos a partir de princípios básicos seja tão fácil e direta quanto possível. Mach contou a história da mecânica para apoiar este raciocínio. Em sua visão, Newton concluiu a primeira fase da história da mecânica. As leis de Newton, que Mach considerou como baseadas em observações, foram os princípios a partir dos quais, sem o auxílio de novos princípios, podem ser compreendidos todos os casos mecânicos que ocorrem na prática. A mecânica do século XVIII, no entender de Mach, pertence à segunda e à terceira fases. Os vários princípios (aceleraçôes reversas, vis viva, ação mínima, etc) são implicados pelas leis de Newton, sendo tentativas de organização econômicas de deduções no contexto da mecânica. A fase de formulação consistiu na criação de uma mecânica analítica iniciada por Euler e completada por Lagrange. Os interesses principais de Mach - a conclusão da fase dedutiva em mecânica através dos princípios de Newton e ausência de metafísica em toda a estrutura tem o efeito de tornar o século XVIII, em sua visão, um período sem eventos e sem inspiração em mecânica.

A Historie de la mécanique ${ }^{8}(1950)$ de Dugas, embora mais histórica e menos partidária de uma visão particular da ciência, dá a mesma impressão da mecânica do século XVIII que Mach: "A mecânica clássica foi moldada no século XVII. A tarefa remanescente de organizá-la e desenvolver seus princípios gerais, foi o trabalho do século XVIII". A criação desta mecânica foi feita pelos três grandes: Galileu, Huygens e Newton; Dugas ordena sua apresentação do século XVII de acordo com pessoas. O século XVIII recebe um tratamento diferente: Dugas conta a história ordenada pelos princípios (trabalho virtual, forças vivas, ação mínima) e subsetores (tais como hidrostática), encerrando a narrativa com uma seção sobre Lagrange. Segundo Dugas, através desse "o trabalho coletivo do século XVIII finalmente alcança uma ciência ordenada, cuja forma se aproxima da perfeição".

Dessa maneira, os historiadores moldaram nossa visão do século XVIII em matemática e mecânica. Porém a estática não é uma característica da mecânica e, por conseguinte, não tornou inerte o progresso de sua história. 
9. I. Newton (1643-1727) - Philosophiae naturalis principia mathematica, 1 ed., Cambridge 1687, 2 ed., Londres 1713, 3 ed Londres 1726 (conforme The Mathematical papers of Isaac New ton, vol. VI, 1684-1691, D. T. Whiteside ed., Cambridge U.P., 1974)

10. C. Truesdell (n. 1919) - a. Rational fluid mechanics, 1687 . 1765, L. Euler, Opera omnia (II) 12,1954

b. "I. The First three sections of Euler's treatise on fluid mechanics (1766); II. The Theory of ae rial sound (1687-1788); III. Rational fluid mechanics (1765-1788), L. Euler Opera omnia (II) 13, 1956.

c. "The Rational mechanics of flexible on elastic bodies, 1638 1788, L. Euler Opera omnia (II) 112,1960

11. C. Truesdell - Essays in the history of mechanics, Springer Verlag, N. York, 1968. ledicão brasileira revista e aumentada em fase de publicação pela Editora da Universidade de Brasília)

12. L. Euler - a. Découverte d'un nouveau principe de méca. nique, Mémoire de l'academie des sciences de Berlin 6 (1750), $1752,520-532$ - Opera omnia (II) $5,81-108$.

b. Nova methodus motum corporum rigidorum determinandi, Novi comm. academiae scientiarum Petropolitanae 20 (1755) 1776, 208-238 - Opera omnia (II) 9, 99-125.

\section{A Abordagem de Truesdell}

Desde 1950 o ponto de vista simplório de que tudo em mecânica até Einstein está implícito nas leis de Newton tem sido efetivamente contestado. Não mais podemos passar sobre o século XVIII como um período que meramente explorou a rica mina cuja entrada foi aberta pelos Principia ${ }^{9}$ de Newton. Pelo contrário hoje estamos conscientes de que as leis de Newton não implicam a totalidade da mecânica. Começamos a ver que foi no século XVIII, em lugar do século XVII, que os fundamentos e principais conceitos da mecânica foram formulados. De fato o próprio programa da ciência da mecânica aparece como uma criação desse século.

Este profundo discernimento da história da mecânica nos foi aberto através do trabalho de um renomado pesquisador, estudante dedicado dos mestres e historiadores da ciência, Clifford Ambrose Truesdell III. O núcleo de sua contribuição ao conhecimento da mecânica do século XVIII é encontrado em suas três magníficas introduções ${ }^{10}$ aos volumes da Opera omnia de Euler, a síntese explanativa dos quais, aditado pela visão do anterior e com uma melhor avaliação do decorrente no século XIX, é o conteúdo do seu modestamente entitulado Essays in the History of Mechanics" ${ }^{11}$.

A representação de Truesdell da mecânica do século XVIII é mais estruturada, mais rica e mais excitante que os trabalhos anteriores. Porém possui uma simplicidade fundamental decorrente do ponto de vista do autor sobre o seu assunto. Ele escreve a história da 'mecânica racional', isto é, a ciência matemática axiomatizada da mecânica. Esta não é a mecânica à qual os físicos estão acostumados, mas sim uma parte da matemática pura, tratada pelos 'mecanicistas'.

Apenas recentemente, há pouco mais de vinte anos, a mecânica racional alcançou o estágio de uma ciência verdadeira axiomática. Trata-se de um discernimento muito recente o de que os dois axiomas básicos da mecânica racional são os princípios do momentum linear e o do momento de momentum. Desses axiomas a mecânica racional deduz as equações diferenciais que governam o movimento dos sistemas mecânicos. Tais sistemas são caracterizados por equações constitutivas; podendo ser constituídos de pontos mássicos ou corpos rígidos; podem envolver fluidos e neste caso as equações constitutivas requerem um conceito bem definido de 'pressão', ou podem envolver corpos flexíveis ou elásticos, neste caso necessitando de um conceito bem definido de 'tensão'. As equações diferenciais deduzidas dos axiomas, combinadas com as equações constitutivas, implicam completamente no movimento do sistema. A determinação adicional daquele movimento é uma questão de matemática (certamente não desprezada pelos mecanicistas), qual seja a de resolver as equações diferenciais.

Esse estilo da mecânica racional foi a criação do século XVIII e não do XVII. Sua história, conforme Truesdell a conta, possui uma estrutura simples e clara e ápices óbvios: a formulação dos princípios do momentum linear e do momentum de momento, ambos por Euler $^{12}$ em 1750 e 1775 respectivamente, o reconhecimento e uso 
13. A. L. Cauchy (1789-1857) Recherches sur l'equilibre et le mouvement intérieur des corps solides ou fluides, elastiques ou non elastiques, Bull. Soc. Philomatique $9,1823,9-13$, Oeuvres (II) $2,300-304$

14. L. Euler - Mechanica sive motus scientia analytice exposita, São Petersburgo, 1736, Opera omnia (II) 1,2 correto do conceito de pressão, ainda por Euler em uma série de trabalhos em hidráulica nos anos vizinhos a 1750 a partir do trabalho de Jean Bernoulli, e a "criação e desdobramento do conceito" de tensão coroada pela introdução por Cauchy ${ }^{13}$ em 1822 do 'tensor' de tensões, evidentemente não reconhecido como tal na época. Assim as principais peculiaridades da nova representação apresentada por Truesdell da mecânica do século XVIII são as seguintes: Em 1750 Euler formulou pela primeira vez o princípio do momentum linear em sua completa generalidade. O princípio estabelece que, para um corpo de massa $M$ e posição x, $y, z$ no espaço, sujeito a uma força de componentes $P, Q, R$ tem-se a notação de Euler I. $2 M d d x=P d t^{2}$, I/. $2 M d d y=Q d t^{2}, I / l .2 M d d z=R d t^{2}$ (conforme Truesdell ${ }^{10}, A p$. XLII-XLV com relação ao sistema de unidades usado por Euler). Euler tornou claro que as equações se aplicam a todos os sistemas mecânicos, discretos (nesse caso somando-se sobre as massas) e contínuos (nesse caso $M, P, Q, R$ devendo ser tomados como diferenciais, efetuando-se a integração ao longo do sistema ou dos subsistemas a considerar). No dizer de Euler"... Le principe que je viens d'établir contient tout seul tous les principes qui peuvent conduire à la connaissance du mouvement de tous les corps. de quelque nature qu'ils soient".

Essas equações são conhecidas como 'equações de Newton; mas Truesdell argumenta detalhadamente que trata-se de uma percepção inadmissível ler tais equações no segundo axioma ou lei de movimento de Newton que estabelece que "a variação do movimento é proporcional à força motriz impressa, e é efetivada na direção da reta segundo a qual a força atua". A formulação de Newton permaneceu aquém da generalidade fornecida pela fórmula matemática; nem Newton utilizou sua segunda lei para estabelecer equações diferenciais do movimento para sistemas de mais de dois corpos, quanto mais para meios contínuos.

Truesdell argumenta que Euler deu ao princípio sua total generalidade. A formulação do mesmo em termos de equações diferenciais em coordenadas retangulares permite a aplicação do princípio diretamente a qualquer configuração de corpos no espaço tridimensional. Este ganho de generalidade matemática e simplicidade éilustrado pela comparação com a Mechanica ${ }^{14}$ de Euler de 1736, na qual, na busca de um princípio geral que incorporasse a segunda lei de Newton, Euler teve de trabalhar um completo aparato de geometria diferencial para curvas reversas.

Além do mais, Euler percebeu que o princípio se aplica igualmente a cada subsistema de qualquer sistema dado e que através disso fornece a equação do movimento para muitos sistemas. Em particular sua aplicabilidade e subsistemas infinitesimais tal como diferenciais de volume em fluidos, Ihe dá a posição de princípio fundamental da mecânica do contínuo. De fato, no artigo em que Euler publicou o "novo princípio", ele o utilizou para deduzir as 'equações de Euler' para o movimento de corpos rígidos.

O segundo axioma da mecânica racional iguala a taxa temporal de variação do momento de momentum ao torque total. Este é um princípio independente da mecânica, embora em certos casos mui- 
tão a demora? Conforme argumenta Truesdell, os sucessos da teoria em casos restritos eram tão grandes que ocultaram a unificação: "nada é tão difícil de superar quanto um corpo de conhecimento verdadeiro porém especial".

Finalmente torna-se possivel reavaliar os méritos dos contribuidores individuais da mecânica. Um que se beneficiou grandemente disso foi Jacques Bernoulli. Suas realizações em mecânica foram ensombradas pelas de Newton, e em matemática o trabalho de seu brilhante e impetuoso irmão atraiu maior atenção. Aquele não deixou qualquer magnum opus, porém escondeu sua perspicácia em anotações privadas e em uns poucos artigos, assim, não tem recebido muita atenção dos historiadores da mecânica. Porém Truesdell, buscando as origens da mecânica racional como ele a vê, encontra muitos e profundos vislumbres no trabalho de Jacques Bernoulli e os expõe.

Entretanto a maior mudança de foco refere-se a Euler. Os gigantes de histórias anteriores tais como D'Alembert e Lagrange são restritos ao seu tamanho normal, porém Euler sobressai acima de todos.

Certamente, em grande parte, Truesdell estabelece as regras de sua história e ao atribuir os conceitos e princípios fundamentais da mecânica racional a Euler em lugar de a outros, defende muito bem sua tese. Ele tem um ponto de vista bem definido sobre a mecânica cuja história escreve; existe basicamente apenas uma única tal mecânica, de modo que as coisas são certas ou erradas dentro dessa estrutura. De todos os autores em mecânica do século XVIII é Euler aquele cujo trabalho mais se aproxima a esse estilo de mecânica, e este é o motivo pelo qual ele domina o cenário na história de Truesdell.

Truesdell explica repetidamente de qual ponto de vista considera a história da mecânica. Alguns leitores lastimarão esse forte parti pris e as preferências e desgostos a ele ligados. Tal lástima entretanto, tem pouco sentido. Dificilmente imagina-se que sem tais fortes pontos de vista possa se produzir um corpo de pesquisa histórica tão coerente e unificado em estilo como no trabalho de Truesdell. Por outro lado, o leitor deve ter em mente que a partir do ponto de vista expresso por Truesdell um certo número de aspectos da mecânica do século XVIII recede ao pano de fundo. Assim, tendo em vista que na mecânica racional axiomática os princípios devem ser formulados claramente e de modo geral, o princípio das acelerações reservas de D'Alembert não desempenha um papel fundamental no registro de Truesdell, por ser restrito e por seu autor não havêlo formulado bem.

Em mecânica racional os princípios são axiomas ou dedutíveis de axiomas; seus fundamentos metafísicos não interessam ao mecanicistas, por conseguinte Truesdell devota pouca atenção, por exemplo, à controvérsia sobre a vis viva e seu cenário filosófico, ou à controvérsia sobre o princípio da ação mínima.

Também em mecânica racional as entidades fundamentais 
não definidas ou conceitos primitivos são força e torque, os princípios básicos são equações diferenciais envolvendo essas entidades, e as especificações especiais dos sistemas estudados são expressas em equações constitutivas. A maior parte dos princípios e formalismos desenvolvidos no século XVII para unificar o tratamento de problemas mecânicos, tais como o princípio de D'Alembert, o princípio do trabalho virtual, e o formalismo de Lagrange, não referiamse a força e torque, não separavam claramente os princípios das equações constitutivas e não eram completamente gerais. Assim, esses princípios e métodos, que em histórias anteriores eram o tema central da estória da mecânica do século XVIII, receberam pouca ênfase no relato de Truesdell. Isto explica a queda dramática de apreciação por Lagrange. O formalismo deste, aclamado por Dugas e praticamente todos os escritores anteriores sobre o assunto como a unificação suprema da ciência da mecânica, não é um princípio no sentido acima e não é geral, daí na versão de Truesdell ser Lagrange colocação sob a sombra de Euler.

Por ser a mecânica racional uma ciência axiomática e não experimental, sendo sua relação com a experiência a mesma que a da geometria, Truesdell argumenta que a prática não teve qualquer efeito positivo sobre a mecânica racional no século XVIII, e que os mecanicistas da época foram sábios em desconsiderar a prática. Aqueles que buscam relações diretas ou indiretas da ciência com a tecnologia no trabalho de Truesdell encontrarão tão somente evidência negativa.

Observados esses pontos, perfeitamente a contento dos estudiosos da moderna mecânica racional, os ensaios de Truesdell são de extrema valia à história da matemática e da mecânica. Eles se baseiam em um estudo extenso e detalhado das fontes primárias, provêem uma representação nova, claramente estruturada, da mecânica do século XVIII, na qual os campos antes negligenciados da mecânica do contínuo recebem sua devida atenção. Ressaltam também, mais limpidamente que a qualquer outro tempo, o interrelacionamento entre a matemática e a mecânica. Historiadores da ciência e cientistas matemáticos interessados no assunto se beneficiarão grandemente dessas contribuições resultantes da observação do conselho de Abel para "estudar os mestres, não seus discípulos".

A matemática no século XVIII possuia uma interação intensa e mais direta com aplicações que em qualquer outro período. Em épocas anteriores o escopo das artes e ciências matemáticas era muito menor, e no século XIX a matemática pura tornou-se uma disciplina independente, criando uma grande distância entre si e as aplicações matemáticas, uma distância ainda sentida como muito vasta.

\section{Epllogo}

No século XVIII a maior parte do trabalho em matemática pura e nas ciências altamente matematizadas como a mecânica e a astronomia tomavam lugar nas Academias. Essas instituições de ciência características da época eram instituições do Estado, sendo fomentadas por monarcas iluminados, pois uma academia florescente, com cientistas famosos internacionamente, emprestava brilho aos 
15. Jean Bernoulli (1667-1748) Hydraulica nunc primum detecta ac demonstrata ex fundamentis pure mechanicis. 1743, (indicado pelo autor como 1732), J. Bernoulli, Opera omnia 4.
16. A. L. Cauchy - De la Pression ou tension dans un corps solide, Ex. de Math. 2 (1822), 1827, 42-56, Oeuvres (II) 7, 60-78. to restritos possa ser dedutível do princípio do momentum linear; Truesdell observa que muitos físicos não estão conscientes dessa independência. O princípio foi formulado como um axioma independente da mecânica por Euler em 1775 na forma:
IV. $\int z d M\left(\frac{d d y}{d t^{2}}\right)-\int y d M\left(\frac{d d z}{d t^{2}}\right)=i S$
V. $\int x d M\left(\frac{d d z}{d t^{2}}\right)-\int z d M\left(\frac{d d x}{d t^{2}}\right)=i T$
VI. $\int y d M\left(\frac{d d x}{d t^{2}}\right)-\int x d M\left(\frac{d d y}{d t^{2}}\right)=i U$.

onde $\mathrm{S}, \mathrm{T}, \mathrm{U}$ são as componentes do torque total e i representa $2 \mathrm{~g}$, um fator dimensional acrescido às equações conforme alertamos anteriormente. Por outro lado, I, II e III anteriores são re-escritas como:

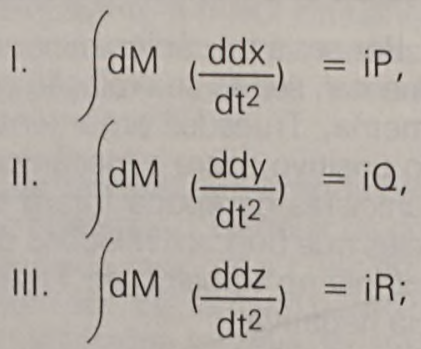

completando as Formulae generales pro motu corporum rigidorum a viribus quibuscunque sollicitatorum.

Os estudos de Euler sobre a forma de vigas elásticas fletidas o levaram a concluir tal independência. Uma forma primitiva do princípio já ocorre no trabalho de Jacques Bernoulli e Truesdell traça então o desenvolvimento subseqüente do princípio e da percepção de sua independência do princípio do momentum linear.

Tanto quanto os princípios, a estória dos conceitos de pressão e de tensão, necessários às equações constitutivas, provêem uma estrutura adicional à representação. O conceito de pressão interna de um fluido tem sua pré-história nos trabalhos de Arquimedes, Stevin, Pascal, Newton e Clairaut. O conceito ocorre explicitamente na Hidráulica de Jean Bernoulli ${ }^{15}$, para fluidos em tubos. Euler o estendeu ao caso de fluidos gerais ocupando qualquer parte do espaço tridimensional. Com este conceito geral e o princípio do momentum linear, construiu no período 1750-1766 uma teoria completa de hidrodinâmica. Entretanto a compreensão da tensão, notavelmente o reconhecimento de que trata-se de um tensor, não ocorreu durante o século XVIII. A pressão interna é uma forma especial da tensão conforme ocorre em fluidos. Outros corpos contínuos deformáveis especiais foram estudados no século XVIII, tal como a catenária e a cinta elástica, e o conceito de tensão ocorre nesses estudos, porém envolvem apenas casos especiais, e por conseguinte, não conduziram à total compreensão do conceito. Não foi senão em 1822 que Cauchy formulou o conceito geral de tensão, o aperfeiçoamento de seu teorema de representação vindo a ser publicado em $1827^{16}$. 
17. J. R. D'Alembert (1717-1783) - a. Recherches sur la courbe que forme une corde tendue mise en vibration. Hist. Acad. Sci. Berlin 3 (1747), 1749, 214-219.

b. Suite des recherches sur la courbe que forme une corde tendue, mise en vibration, ibid, 220249.

18. L. L. Lagrange - Application de la méthode exposée précédent à la solution de différens problèmes de dynamique. Misc. Taur. 22. (1760-1761), 1762, 196-298, Oeuvres 1, 365-468.
A nova abordagem da história da mecânica por Truesdell é de grande importância para a história da matemática pois a mecânica racional se constituiu no contexto do qual as partes mais interessantes da matemática do século XVIII se desenvolveram. Todos os grandes matemáticos desse período - os Bernoullis, Clairaut, D'Alembert, Euler, Lagrange e outros, trabalharam tanto em matemática como em ciências matemáticas e não consideravam esses campos como distintos. Da mesma forma Truesdell não faz tal separação e seus estudos históricos mostram, melhor que o poderia fazer qualquer história em separado da matemática ou da mecânica, a impressionante riqueza e fecundidade do entrelaçamento entre essas disciplinas no século XVIII. Os dois campos que se desenvolveram na análise eram intimamente ligados à mecânica; a teoria das equações a derivadas parciais foi, no dizer de Truesdell, "o grande presente da mecânica do contínuo à análise". O problema da corda vibrante conduziu à primeira solução completa de uma equação a derivadas parciais (a equação das ondas), completada ao final de 1746 por D'Alembert ${ }^{17}$; e Euler trabalhou muito na teoria e nas soluções de tais equações em suas pesquisas em hidrodinâmica. O cálculo variacional, originado parcialmente no estudo de problemas mecânicos tais como a braquistocrona por volta de 1700 , foi desenvolvido como uma teoria puramente analítica por Euler e Lagrange ${ }^{18}$, sendo logo aplicado a muitos problemas da mecânica.

O trabalho de Truesdell demonstra em detalhe o entrelaçamento entre a mecânica e a matemática e afirma que a partir aproximadamente de 1730 "a mecânica do contínuo deu origem a todos os principais problemas novos da análise". Os estudos de Jacques Bernoulli sobre a elástica deram origem às funções elíticas; a solucão geral de uma equação diferencial linear de coeficientes constantes determinada por Euler se originou em seu estudo da oscilação de uma cinta elástica; o estudo das vibrações de uma corda dependurada livremente envolvia funções de Bessel; problemas relacionados, tais como as vibrações de membranas estudadas por Euler, conduziam aos conceitos de freqüências próprias e funções próprias.

A estrutura dada por Truesdell à história da mecânica no século XVIII é muito frutífera. Ela traz clareza e ordem e, de modo não constritivo, a riqueza dos desenvolvimentos desenrolam-se em seu interior. Além do mais, esta ordem e clareza torna possível perguntar e responder questões sugestivas. Assim, há a questão da influência de Newton - tão responsável e tão exagerada - e o papel dos Principia do desenvolvimento da mecânica do século XVIII. Ao discutir esta questão Truesdell aponta as partes de mecânica que Newton não tocou de forma alguma: mecânica do contínuo e hidrodinâmica. Mostra que muitas tradições, conceitos e problemas nesses campos entravam no século XVIII circunavegando os Principia.

Outra questão é a de porque levou tanto tempo para a mecânica dos corpos elásticos alcançar o tratamento coerente dado finalmente por Cauchy através da introdução do tensor de tensões. Como mostra Truesdell os conceitos requeridos para esta unificação repousavam todos nas mãos de Euler por volta de 1770 . Porque en- 
19. Swift, J. (1667-1745) - Gulliver's travels, (Ed. de Motte, Londres, 1726; Ed. de Faulkner, Dublin, 1735) reimpressão desta última, Oxford, Basil Blackwell, 1959. (Tradução brasileira dessa edição, a menos de apêndices, Viagens de Gulliver, S. Paulo, Abril Cultural, 1979). seus reinos e servia uma função útil ao Estado. O Estado podia se valer de aconselhamento científico de valor em assuntos militares, navais e econômicos bem como em questões de infraestrutura e educação.

Para saber o que era uma Academia do século XVIII, é ilustrativa a representação contida na terceira viagem de Gulliver, publicada um ano antes da ida de Euler para São Petersburgo. Swift ${ }^{19}$ tinha em mente a Royal Society de Londres, porém a luva se adapta de igual modo às academias mais formais do continente (Paris, Berlim, São Petersburgo...).

\section{Primeiramente, havia a classe dos matemáticos:}

"... uma raça de mortais de formas, vestes e feições tão singulares. Tinham a cabeça inclinada, ou para a direita, ou para a esquerda; um dos olhos era voltado para dentro e outro, diretamente para o zênite. Adornavam-Ihes os trajes exteriores figuras de sóis, luas e estrelas, entremeadas de representações de violinos, flautas, harpas, trombetas, guitarras, cravos e muitos outros instrumentos musicais desconhecidos na Europa. Vi, aqui e ali, muitos com vestes de criados que traziam na mão uma bexiga inchada, amarrada com um mangual à ponta de uma bengala. Em cada bexiga havia uma pequena quantidade de ervilhas secas, ou pedrinhas, segundo mais tarde me informaram. Com essas bexigas batiam eles, de quando em quando, na boca e nos ouvidos dos que lhes ficavam próximos, prática essa cujo alcance não pude então conceber. Parece que o espírito dessas pessoas anda de tal forma absorto em profundas especulações, que não podem falar nem atender aos discursos dos outros, sem que as esperte alguma ação externa sobre os órgãos da fala e da audição; dessa maneira, as que se podem dar a esse luxo têm sempre um batedor (o original é climenole) a serviço da família, como um dos seus criados; nem jamais saem de cada ou fazem visitas sem ele. E o ofício desse servidor, quando se acham reunidas duas, três ou mais pessoas, consiste em bater delicadamente com a bexiga na boca de quem fala e no ouvido direito daquele ou daqueles a quem se dirige o orador. Esse batedor é também empregado para acompanhar, diligente, o amo em seus passeios e dar-lhe quando necessário uma delicada batida nos olhos; porque ele, de ordinário, anda de tal forma embebido em suas cogitações, que corre manifestamente perigo de cair em todos os precipícios e de bater com a cabeça em todos os precipícios e pelas ruas, de atirar os outros ou ser pelos outros atirado à sarjeta.

É forçoso dar ao leitor essas informações, sem as quais não poderia ele, como eu, entender o procedimento dessa gente, enquanto me conduzia, pelas escadas, ao cimo da ilha e, de lá, ao palácio real. Enquanto subíamos, esqueceram-se várias vezes do que estavam fazendo, e deixaram-me sozinho, até que os batedores lhes despertaram novamente a memória: pois pareciam de todo ponto indiferentes à vista de minhas roupas e feições estranhas e aos gritos da plebe, cujos pensamentos e cujo espírito eram mais desembaraçados.

Entramos, afinal, no palácio e passamos à sala das audiências, 
onde vi o rei assentado em seu trono, ladeado de pessoas de primeira qualidade. Defronte do trono havia uma mesa grande cheia de globos e esferas, e instrumentos matemáticos de toda sorte. Sua Majestade não nos deu a mínima atenção, suposto que a nossa entrada fosse acompanhada de ruído suficiente, produzido por todas as pessoas pertencentes à corte. Mas achava-se então engolfado num problema; e tivemos de esperar pelo menos uma hora, antes que conseguisse resolvê-lo. Havia, de cada lado, um jovem pajem em pé, com um moscadeiro na mão, e quando o viram ocioso, um deles bateu-lhe delicadamente na boca e o outro, no ouvido direito; o rei estremeceu como alguém que acordasse de repente e, olhando para mim e para os meus acompanhadores, lembrou-se da ocasião da nossa vinda, de que já fora informado anteriormente. Pronunciou algumas palavras; um rapaz munido de um moscadeiro veio imediatamente parar ao pé de mim, e bateu-me delicadamente no ouvido direito; mas fiz sentir como pude, por meio de sinais, que não me era necessário tal instrumento; o que segundo verifiquei depois, levou Sua Majestade e toda a corte a formarem péssimo conceito de meu entendimento. O rei, segundo supus, fez-me diversas perguntas, e eu me dirigi a ele em todas as línguas que sabia. Quando se verificou que eu não podia nem compreender nem ser compreendido, fui conduzido por sua ordem a uma habitação do palácio lesse príncipe distinguia-se mais do que os antecessores pela hospitalidade para com os estrangeiros), onde se designaram dois criados para servir-me. Trouxeram-me o almoço, e quatro pessoas de qualidade, que me lembra ter visto muito próximas da pessoa do rei, fizeramme a honra de almoçar comigo. Serviram-nos duas entradas, de três pratos cada uma. Na primeira entrada havia uma pá de carneiro, cortado sob a forma de um triângulo eqüilateral, um pedaço romboidal de carne de vaca, e um pudim cicloidal. A segunda entrada consistia em dois patos enfardelados de forma de violino; salsichas e pudins que semelhavam oboés, e peito de vitela em forma de harpa. Os criados cortaram-nos o pão em cones, cilindros, paralelogramos e outras figuras matemáticas.

... Observando aqueles a quem a quem me confiara o rei quão mal eu me trajava, ordenaram viesse um alfaiate, na manhã seguinte, tomar-me as medidas para um fato completo. Esse artesão fezo seu ofício de maneira diversa da que empregam na Europa os seus colegas. Tomou primeiro a minha altura por meio de um quadrante e, a seguir, com régua e compassos, descreveu as dimensões e contornos de todo o meu corpo, passando para o papel todos os dados; e seis dias depois trouxe-me as roupas muito malfeitas e inteiramente desconformes, por Ihe haver sucedido enganar-se num algarismo em seus cálculos. Consolou-me, contudo, observar que tais acidentes eram freqüentíssimos e que a eles se dava muito pouca importância.

... O rei e a nobreza, cortesãos e funcionários, depois de prepararem todos os instrumentos musicais, tocaram-nos durante três horas, sem descontinuar, de sorte que o ruído quase me ensurdeceu; nem me foi possível adivinhar a ocasião disso, até que me explicou o professor. Disse ele 'que o povo da ilha tinha os ouvidos adaptados para ouvir a música das esferas, que soava sempre em certos 
períodos, e a corte executou agora a sua parte, com os instrumentos em que cada qual mais sobressaia'.

... O conhecimento que eu tinha da matemática muito me ajudou no aprendizado da fraseologia daquele povo, que depende em grande parte dessa ciência e da música; em que eu também não era leigo. As idéias deles se referem perpetuamente a linhas e figuras. Quando, por exemplo, querem exalçar a beleza de uma mulher, ou de outro animal qualquer, descrevem-na por meio de rombos, círculos, paralelogramos, elipses e outros termos geométricos, ou por meio de palavras de arte, tiradas da música, que fora aqui desnecessário repetir. Observei na cozinha do rei toda sorte de instrumentos matemáticos e musicais que serviam de modelo para a corte dos pedaços de carne apresentados à mesa de Sua Majestade."

Deve ser observado que os matemáticos do lluminismo partiIhavam de uma paixão comum pela música. O próprio Euler escreveu um tratado sobre harmonia, que até hoje não foi suplantado; projetou escrever um tratado sobre composição e publicou alguns pequenos artigos sobre a função das dissonâncias. D'Alembert por sua vez escreveu um tratado sobre música. Em outro ensaio abordaremos esse relacionamento.

Na cidade científica de Laputa,

"... As casas são muito mal construídas, as paredes esguelhadas, por maneira que se não encontra um único ângulo reto em nenhuma habitação; e esse defeito nasce do desdém que consagram à geometria prática, menosprezada por vulgar e mecânica; sendo as instruções fornecidas por eles demasiado sutís para o intelecto dos seus trabalhadores, o que ocasiona perpétuos equívocos. E posto sejam assaz destros diante de um pedaço de papel, no manejo da régua, do lápis e do compasso, nunca vi nos atos comuns e na maneira de viver povo mais tosco, desajeitado e desastrado, nem tão lento e confuso em suas concepções sobre todos os outros assuntos, tirante a matemática e a música. São péssimos raciocinadores e violentamente inclinados à oposição, exceto quando acertam sustentar a opinião verdadeira, o que raro sucede. De todo ponto alheios à imaginação, à fantasia e à invenção, não têm palavras em sua língua para expressar essas idéias; pois todo o círculo dos seus pensamentos e do seu espirito é limitado pelas duas ciências mencionadas.

A maioria, e especialmente os que se dedicam à parte astronômica, deposita muita fé na astrologia judiciária, embora se corra de confessá-lo em público. Mas o que mais admirei, e julguei absolutamente inexplicável, foi a vigorosa propensão que neles observei para as novidades e para a política, e o fato de estarem perpetuamente a indagar dos negócios públicos, ou dar a sua opinião sobre assuntos de Estado e discutir apaixonadamente cada letra das plataformas dos partidos. Observei, com efeito, a mesma disposição entre a maioria dos matemáticos que conheci na Europa, se bem nunca pudesse descobrir a menor analogia entre as duas ciências; a menos de supor essa gente que, tendo o menor dos círculos o mesmo número de graus que o maior, o regular e o governar o mundo não requerem maiores habilidades que o manejar e o girar um globo: tenho antes, 
porém, que essa qualidade procede de um comuníssimo defeito da natureza humana, que nos desperta principalmente a curiosidade e o interesse pelos assuntos que menos nos dizem respeito, e para os quais estamos preparados pelo estudo ou pela natureza.

Vive esse povo numa perpétua inquietação e nunca se goza de um minuto de tranqüilidade espiritual: procedendo as suas preocupações de causas que afetam muito pouco o resto dos mortais. (...)

... Tão constantemente os assusta o receio deste e de outros perigos iminentes dessa ordem, que não conseguem dormir, tranqüilos, em suas camas, nem saborear-se dos prazeres e distrações comuns da vida... ."

Os matemáticos descritos por Swift viviam em uma ilha suspensa magneticamente no ar, com movimentos precisamente controlados de modo a dominar a terra abaixo dela. A esse nível estavam os praticantes das ciências naturais e aplicadas, que habitavam a Grã Academia de Lagado:

"... Essa academia não é constituída de um só edifício, mas de uma série de várias casas de ambos os lados da rua que, havendo-se estragado, foram adquiridas para esse fim e nele aplicadas.

... Em cada sala há um ou mais projetistas; e acredito que eu não poderia ter visitado menos de quinhentas.

O primeiro homem que encontrei era magro, tinha o rosto e as mãos fuliginosas, cabelos e barba compridos, e andava roto e sapecado em várias partes. As roupas, a camisa e a pele eram todas da mesma cor. Havia oito anos que estudava um projeto para extrair raios de sol dos pepinos, metidos em redoma hermeticamente seladas, e aquecidos ao ar nos verões crus e inclementes. Disse-me não duvidar de que, dentro de mais oito anos, Ihe seria possivel fornecer luz solar aos jardins do governador a um preço razoável; mas queixou-se da escassez de suas provisões e rogou-me lhe desse alguma coisa como estímulo ao engenho, um especial por ter sido aquele ano muito mau para os pepinos. Fiz-lhe um pequeno presente, pois o meu hospedeiro, conhecendo-Ihes o hábito de pechincharem a todos os visitantes, me dera algum dinheiro.

Entrei em outra sala e já me dispunha a retroceder, à pressa, quase asfixiada pelo mau cheiro, quando o meu guia me empurrou para a frente, conjurando-me, num sussuro, que me não mostrasse repugnado, pois isso seria tomado como ofensa; e, por conseguinte não me atrevi sequer a tapar o nariz. O projetista desta cela era o sábio mais antigo da academia; o rosto e a barba eram de um amarelopálido; tinha as mãos e as roupas besuntadas de imundícies. Quando Ihe fui apresentado, abraçou-me com entusiasmo (cumprimento que eu teria perfeitamente dispensado). Desde que ingressara na academia, a sua função consistia em reconverter o excremento humano nos alimentos originais, separando-lhe as diversas partes, renovando a coloração que recebe da vesícula biliar, extinguindo-lheo cheiro e retirando-lhe os restos da saliva. Recebia da sociedade uma ração semanal, a saber, um vaso cheio de imundície humana, do tamanho de um barril de Bristol. 
Vi outro que forcejava para transformar o gelo em pólvora, pela calcinação; e que também me mostrou um tratado escrito por ele sobre a maleabilidade do ferro, que pretendia publicar.

Havia um arquiteto engenhosíssimo, inventor de um novo método de construção de casas, que começava pelo teto e acabava pelos alicerces; que ele justificava com o exemplo de dois prudentes insetos, a abelha e a aranha.

Havia um homem, cego de nascença, que tinha vários aprendizes nas mesmas condições; o seu ofício consistia em misturar as cores para a pintura que o amo os ensinava a distinguir pelo tato $e$ pelo cheiro. Tive, com efeito, o infortúnio de encontrá-los nessa ocasião não muito felizes em suas lições, e ao próprio mestre sucedia-lhe enganar-se quase sempre. Esse artista é muito animado e apreciado por toda a fraternidade.

Em outro aposento, folguei imenso de encontrar um projetista que achara meio de arar a terra com porcos, a fim de poupar despesas do arado, do gado e do trabalho. O método é o seguinte: enterramos, em 1 acre de terra, a 6 polegadas de distância e 8 de profundidade, grande número de bolotas, tâmaras, castanhas e outros frutos ou vegetais de que mais gostam esses animais; a seguir, soltamos seiscentos deles no campo; em poucos dias, terão removido a terra toda à procura do alimento, aparethando-a para a semeadura $e$ adubando-a, ao mesmo passo, com os excrementos: é verdade que até agora se verificou pela experiência serem as despesas e o trabaIho muito grandes, e as colheitas, poucas ou nenhuma. Ninguém duvida, contudo, que essa invenção seja passível de grande aperfeiçoamento.

Entrei em outra sala, em cujo teto e em cujas paredes se viam penduradas teias de aranha, exceto ao nível de uma estreita passagem destinada à entrada e à saída do artista. Quando entrei, ele me pediu, a vozes, que não ihe estragasse os tecidos. Lamentou o erro fatal em que estivera o mundo durante o tempo, empregando o bicho-da-seda, quando havia tão grande cópia de insetos domésticos que se avantajavam infinitamente àquele, porque sabiam não só tecer mas também fiar. E afirmou ainda que, com o emprego das aranhas, se pouparia inteiramente a despesa de tingir a seda; do que de todo me convenci quando ele me mostrou um grande número de moscas lindamente coloridas, com as quais alimentava as suas aranhas, assegurando-nos que os tecidos tomavam a sua cor; e, como as tinha de todos os tons, esperava satisfazer os caprichos de todos, tanto que lhe fosse possível encontrar o alimento adequado para as moscas, feito de certas gomas, óleos e outras substâncias glutinosas, para dar força e consistência aos fios.

Havia um astrônomo que empreendera a tarefa de colocar um relógio de sol no grande cata-vento da casa da câmara municipal, ajustando os movimentos anuais e diurnos da Terra e do Sol, de forma que todas as mudaniças acidentais do vento coincidissem com elas.

Queixei-me de uma crisezinha de cólica; em vista disso, 
conduziu-me o guia a uma sala onde trabalhava um grande médico, famoso por curar essa moléstia mediante operações contrárias do mesmo instrumento. Possuía ele um fole muito grande, cujo bico de marfim, longo e fino, introduzia profundamente no ânus, para extrair o ar que por lá se encontrasse, afirmando que assim conseguia deixar as tripas flácidas como bexiga vazia. Quando, porém, a moléstia se mostrava mais violenta e rebelde introduzia o bico, com o fole cheio de ar e soprava-o no corpo do paciente; a seguir retirava o instrumento para tornar a enchê-lo, obturando completamente o orifício anal com o polegar; e, sendo a operação repetida três ou quatro vezes, o ar adventício precipitava-se para fora em companhia do insalubre (como a água empurrada numa bomba), e o doente sarava. Vi-o fazer as duas experiências num cachorro, mas não observei nenhum efeito em relação à primeira. Concluída a última, o animal estava quase estourando, e fez uma descarga violentíssima, sumamente desagradável para mim e para os meus companheiros. 0 cachorro morreu instantaneamente, e deixamos o doutor procurando restituir-Ihe a vida pelo mesmo processo.

Visitei muitos outros aposentos, mas não molestarei o leitor com todas as curiosidades que observei, em obséquio à brevidade.

Eu vira até então um lado apenas da academia, pois o outro se destinava aos fatores do conhecimento especulativo dos quais direi alguma coisa quando falar de mais uma pessoa ilustre, chamada entre eles o 'artista universal'. Contou-nos ele que havia trinta anos aplicava os seus pensamentos ao progresso da vida humana. Tinha duas salas grandes, cheias de maravilhosas curiosidades, e cinqüenta homens ao seu serviço. Alguns condensavam o ar para o converter numa substância tangível e seca, extraindo o nitro e filtrando as partículas aquosas ou fluidas; outras amaciavam o mármore, para fazer travesseiros e almofadas para alfinetes; outros petrificavam os cascos de um cavalo vivo, para os preservar do atroamento. O próprio artista se empenhava, naquela ocasião, em dois grandes projetos; o primeiro, de semar a terra com os resíduos dos cereais joeirados, onde afirmava estar contida a verdadeira virtude seminal, segundo demonstrou por meio de vários experimentos, que eu não tive a inteligência de compreender. O outro, de impedir, por uma certa composição de gomas, minerais e vegetais, externamente aplicada, o crescimento da lã em dois cordeirinhos; e esperava, num tempo razoável, propagar por todo o reino a espécie dos carneiros pelados.

Atravessamos um passeio para chegar à outra parte da academia, onde, como eu já disse, residiam os projetistas empenhados em estudos especulativos.

O primeiro professor que vi achava-se numa sala muito espaçosa, rodeado de quarenta alunos. (...) disse-me que eu talvez me admirasse de vê-lo empenhado num projeto de aperfeiçoar o conhecimento especulativo por meio de operações práticas e mecânicas. Mas o mundo não tardaria a advertir-se-Ihe da utilidade; ( ...). Todos sabemos quão laborioso é o método usual para chegarmos à compreensão das artes e das ciências; ao passo que, por meio do seu in- 
20. Nicolson, M. \& N. M. Mohler - a. The Scientific Background of the voyage to Laputa, Annals of Science 2, 1937, 299-335.

b. "Swift's 'Flying Island' in the Voyage to Laputa", ibid, 2, 1937. 405-430.

21. Como exemplo de ciência inevitável, H. H. Post ilustra "um acelerador com três saidas. Alvos distintos são inseridos em cada uma das saidas, e um assistente de pesquisa fixado a cada saida por um ano, medindo a intensidade da dispersão em várias direções. Ao final do ano, o assistente é removido, publica seus danos e the é dado um título de PH.D".

22. Truesdell, C. The role of mathematics in Science as exemplified by the work of the Bernoullis and Euler, Verhandl. Naturf. Ges. Basel, 91, 1981, 5-22. vento, a pessoa mais ignorante poderia, a um preço razoável e com pequeno trabalho corporal, escrever livros de filosofia, poesia, política, direito, matemática e teologia sem a menor assistência do engenho ou do estudo.

... Pretendia reunir para dar ao mundo, com tão ricos materiais, um corpo completo de todas as artes e ciências; o qual, entretanto, poderia ser ainda muito melhorado e facilitado, se o público levantasse fundos para a feitura e emprego de quinhentos quadros semelhantes em Lagado, e fossem os seus diretores obrigados a contribuir para a obra comum com as suas diversas coleções.

... Estive na escola matemática, onde o mestre ensinava os alunos por método que nós, na Europa, dificilmente poderíamos conceber. A proposição e a demonstração eram claramente escritas numa obréia fina, com tinta composta de um corante cefálico, queo estudante engolia em jejum, não podendo comer durante três dias senão pão e água. Digerida a obréia, subia-lhe o corante para o cérebro levando consigo a proposição. O método, contudo, ainda não fora tão bem sucedido como se esperava, em parte por algum erro no quantum ou composição, e, em parte, pela perversidade dos meninos, para os quais é tão nauseoso esse bolo, que, de ordinário, fingem comê-lo e o lançam fora por cima, antes que possa fazer efeito; nem foi ainda possível persuadí-los a cumprir a longa abstinência que exige a prescrição."

Pode-se pensar que estas longas citações de Swift das Viagens de Gulliver nada mais são que uma fantástica paródia; ou como diz a catalogação brasileira da obra - sátira e humor; que nos conduz além do tópico abordado. Pelo contrário, a cada episódio da terceira viagem corresponde uma fonte específica, seja nos Philosophical Transactions ou em outra literatura científica ao alcance de Swift, conforme traçado pelos estudos de Nicolson \& Mohler ${ }^{20}$. A verdade é mais bizarra que a imaginação e, algumas vezes, parece que hoje esquecemos que o abuso de métodos experimentais se assemelha a uma segunda infância da mente humana. Vemos, através de Swift, que no século XVIII estudos "relevantes" eram subsidiados pelos governos, empregando grandes equipes e necessitando aparatos de alto custo, faltando apenas a televisão educativa, os grandes computadores e aceleradores de partículas ${ }^{21}$ para completar nosso cenário atual. Nenhum dos produtos das pesquisas então realizadas visando à melhoria da humanidade conduziram a algo que hoje possamos dar valor. Swift não mencionou as disputas dos acadêmicos nem as finanças precárias das academias là época de Euler como presidente da Académie des Sciences de Berlim, as finanças dependiam da venda de almanaques), mas a realidade presente não difere do que a literatura da época poderia descrever.

Resta a perenidade da matemática. No dizer de Truesdell 22 :

“A disciplina matemática é para a ciência o que a civilização é para o homem. Não consiste na substituição de todo o experimento por raciocínio, mas em fazer uma distinção clara entre o que é medido e o que é deduzido por raciocínio, e em buscar reduzir o tanto quanto possível a necessidade de medidas a cada estágio. 
A matemática utilizada corretamente traz simplicidade, coerência, ordem e beleza as partes da ciência natural que anteriormente pareciam complexas, disjuntas, não-relacionadas, e deselegantes. A crítica e a síntese matemática pode converter dogmas e regras de ofício - cantos sacerdotais e segredos do mister - em compreensão simples que pode vir a ser ensinada às crianças."

Essa é a herança deixada por Euler e os Bernoullis ao buscar problemas cuja solução é proveitosa em si e ainda mais vantajosa pela luz que faz incidir sobre a ciência como um todo; outro nome para isso - difícil de definir porém fácil de reconhecer - é, bomgosto. Será que após dois séculos o estamos perdendo? Queremos concluir com ainda uma outra disgressão, da pena de Euler; então com 24 anos e sete artigos publicados; saiu o protesto formal:

" ... Ė verdade que nunca fui tão aplicado a física quanto a matemática, entretanto duvido muito que se possa trazer do exterior uma pessoa como eu por quaisquer 400 rublos. Em matéria de matemática, penso que o número dos que a levaram tão adiante quanto eu é muito pequeno em toda a Europa, e nenhum desses virá por 1.000 rublos."

Dois anos depois, Euler conseguiu 660 rublos; logo é inútil lainda hoje) discutir com administradores embora seja fácil suplantar o trabalho deles. Afinal, aquele que nunca fez pesquisa científica dificilmente possuirá uma vaga idéia de como qualquer cientista de qualquer período, concebeu, abordou e resolveu um problema científico.

Não quero deixar ao leitor a impressão de que me arvorei de historiador da mecânica, quanto menos da ciência. Uma história verdadeira e competente de qualquer ramo da ciência só pode ser escrita quando o autor tem a sua disposição monografias detalhadas, completas e confiáveis sobre o conteúdo científico - além de ser dotado de vasta experiência - dos trabalhos científicos; caso contrário trata-se apenas de estória...

Nota. Deixei de considerar o texto de I. Szabò, Geschichte der mechanischen Prinzipien und wichtigsten Anwendungen, Basel \& Stuttgart, Birkhäuser Verlag, 1976 por existir uma abordagem critica mais detalhada por Truesdell, "An Essay Review of Geschichte etc", Centaurus 23, $1980,163-175$. 


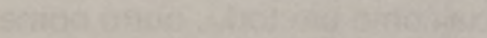

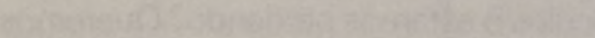

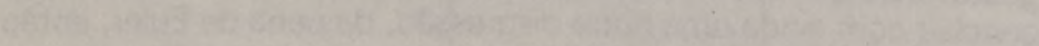

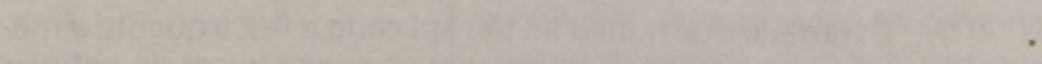

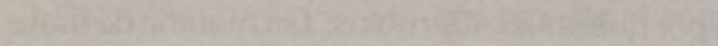

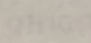

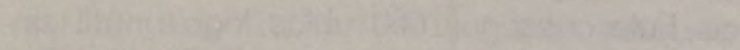

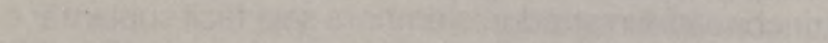

.

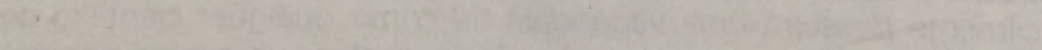

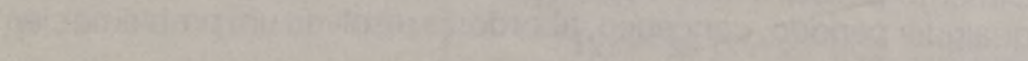

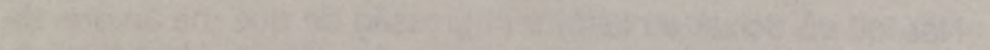

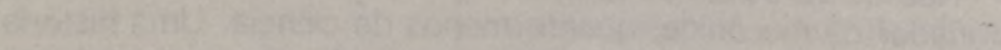

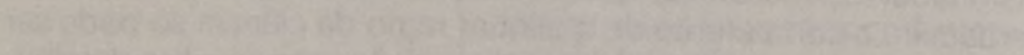

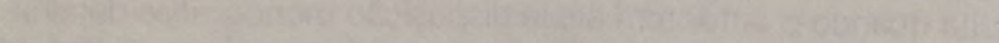

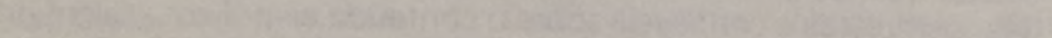

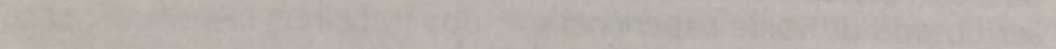

